\section{First Reported Case of Hyperchloremic Non- Anion Gap Metabolic Acidosis in a Patient Undergoing Continuous Bladder Irrigation for Hemorrhagic Cystitis}

\author{
Azka Latif ${ }^{1}$, Joseph Thirumalareddy ${ }^{2}$, Akshat Sood ${ }^{1}$, Sunil Nair ${ }^{3}$, Abubakar Tauseef ${ }^{4}$ \\ 1. Internal Medicine, CHI Creighton University, Omaha, USA 2. Hospital Medicine, Creighton University School of \\ Medicine, St. Joseph's Hospital and Medical Center, Omaha, USA 3. Internal Medicine, Creighton University School of \\ Medicine, Omaha, USA 4. Internal Medicine, Creighton University, Omaha, USA
}

Corresponding author: Abubakar Tauseef, abubakartauseef@creighton.edu
Review began $11 / 25 / 2020$ Review ended 12/08/2020 Published 12/17/2020

๑) Copyright 2020 Latif et al. This is an open access article distributed under the terms of the Creative Commons Attribution License CC-BY 4.0., which permits unrestricted use, distribution, and reproduction in any medium, provided the original author and source are credited.
Categories: Internal Medicine, Nephrology, Hematology

Keywords: hyperchloremic, non-anion gap metabolic acidosis, undergoing, bladder irrigation, cystitis

\section{Introduction}

In patients who have undergone radiation for the treatment of various pelvic malignancies or conditions, there is a possible side effect of radiation-induced hemorrhagic cystitis. Radiation cystitis can present in either an acute or chronic fashion. Late radiation cystitis often presents as gross hematuria and occurs secondary to irritation of the bladder urothelium. Continuous bladder irrigation (CBI) is commonly used for the treatment of hemorrhagic cystitis for evacuation of blood clots and to maintain catheter drainage. Most commonly, CBI is performed using $0.9 \%$ sodium chloride. The urothelium acts as a permeability barrier between urine and blood [1]. One of the main features of bladder includes low diffusive permeability to water [2]. Disruption of this barrier function in certain circumstances such as infections, radiations, toxic chemicals, and mechanical damage leads to reabsorption of fluid and solutes in the blood stream. Herein, we report a 77-year-old female who developed hyperchloremic non-anion gap metabolic acidosis (H- NAGMA) and pulmonary edema secondary to absorption of $0.9 \%$ normal saline (NS) from CBI.

\section{Case Presentation}

A 77-year-old female presented to the ED with a chief complaint of hematuria for one day. The patient had a past medical history of uterine cancer, 10 years prior, for which she received radiation in addition to a hysterectomy with bilateral oophorectomy. The recurrent hematuria and clots in the bladder were previously deemed to be secondary to hemorrhagic radiation cystitis from the previous radiation to the pelvis. During the course of stay, the patient required CBI for removal of clots of up to 12-15 L within the bladder and to prevent urinary retention. On hospital day 3, it was noted that the patient's catheter was no longer draining. Bladder scan showed $500 \mathrm{~mL}$ at this time, and irrigation was attempted with another $780 \mathrm{~mL}$ of NS, after which several clots were noted to pass. Eventually the patient required frequent manual irrigation in order to maintain patency of the Foley catheter. By hospital day 4, the patient developed further abdominal distension and increased work of breathing including desaturation down to 80\%. Chest X-ray was suggestive of fluid overload. Ultrasound abdomen showed no signs of hydronephrosis. Upon reinsertion of a new catheter, $10 \mathrm{~L}$ of fluid was drained, and the patient's shortness of breath began to remit after treatment with diuretics. Daily laboratory testing showed low serum bicarbonate level at $14.0 \mathrm{mmol} / \mathrm{L}$, albumin was $4.5 \mathrm{~g} / \mathrm{dL}$ with a concomitant increase in serum chloride to $118 \mathrm{mmol} / \mathrm{L}$ (Tables $1-2)$. 


\section{Cureus}

\begin{tabular}{|c|c|c|c|c|c|c|c|c|c|c|c|c|c|c|c|c|}
\hline $\begin{array}{l}\text { Days after } \\
\text { admission }\end{array}$ & $\begin{array}{l}\text { Day } \\
1\end{array}$ & $\begin{array}{l}\text { Day } \\
2\end{array}$ & $\begin{array}{l}\text { Day } \\
3\end{array}$ & $\begin{array}{l}\text { Day } \\
3\end{array}$ & $\begin{array}{l}\text { Day } \\
4\end{array}$ & $\begin{array}{l}\text { Day } \\
5\end{array}$ & $\begin{array}{l}\text { Day } \\
6\end{array}$ & $\begin{array}{l}\text { Day } \\
7\end{array}$ & $\begin{array}{l}\text { Day } \\
8\end{array}$ & $\begin{array}{l}\text { Day } \\
9\end{array}$ & $\begin{array}{l}\text { Day } \\
10\end{array}$ & $\begin{array}{l}\text { Day } \\
11\end{array}$ & $\begin{array}{l}\text { Day } \\
12\end{array}$ & $\begin{array}{l}\text { Day } \\
13\end{array}$ & $\begin{array}{l}\text { Day } \\
15\end{array}$ & $\begin{array}{l}\text { Day } \\
18\end{array}$ \\
\hline Sodium & 137 & 138 & 138 & 136 & 136 & 140 & 143 & 147 & 146 & 143 & 142 & 144 & 147 & 144 & 142 & 140 \\
\hline Potassium & 4.7 & 5.0 & 4.7 & 4.7 & 4.3 & 3.9 & 3.8 & 3.4 & 3.8 & 3.2 & 3.8 & 3.7 & 4.0 & $3 . .6$ & 3.5 & 4.2 \\
\hline Chloride & 105 & 107 & 107 & 108 & 107 & 117 & 118 & 122 & 122 & 117 & 119 & 121 & 121 & 118 & 113 & 110 \\
\hline $\mathrm{CO} 2$ & 21.0 & 22.0 & 21.0 & 18.0 & 21.0 & 16.0 & 14.0 & 12.0 & 11.0 & 14.0 & 13.0 & 14.0 & 15.0 & 17.0 & 19.0 & 22.0 \\
\hline Anion gap & 16 & 14 & 15 & 15 & 12 & 11 & 15 & 16 & 17 & 15 & 14 & 13 & 15 & 13 & 14 & 12 \\
\hline Calcium & 9.0 & 8.3 & 8.2 & 8.2 & 8.1 & 6.6 & 6.3 & 6.3 & 6.0 & 6.3 & 7.2 & 7.4 & 7.1 & 7.5 & 7.5 & 7.2 \\
\hline
\end{tabular}

TABLE 1: Basic metabolic profile during hospital stay.

\begin{tabular}{|l|c|}
\hline \hline Chloride, urine & 132 (H) \\
\hline Creatinine urine random & 15 (L) \\
\hline Osmolality random urine & 306 \\
\hline Potassium random urine & 5.7 (L) \\
\hline Sodium, urine & 135 (H) \\
\hline
\end{tabular}

TABLE 2: Urine electrolytes studies done prior to CBI.

$\mathrm{CBI}$, continuous bladder irrigation

Our differential diagnosis included renal tubular acidosis and H-NAGMA secondary to diarrhea. As there was no recent history of diarrhea, it was excluded. To rule out renal tubular acidosis urine studies were performed. Nephrology was consulted, and she was started on $650 \mathrm{mg}$ of sodium bicarbonate three times daily along with a hypotonic bicarbonate infusion according to the guidelines, in order to improve the bicarbonate. Over the course of next few days, the rate of CBI was weaned down, with as needed intermittent manual irrigation. Acidosis was not improving after bicarbonate tablets, but as the CBI was weaned acidosis resolved with improvement of serum bicarbonate $(22 \mathrm{mmol} / \mathrm{L})$ on day 18 .

\section{Discussion}

Most common etiologies of hemorrhagic cystitis are infections, anticancer chemotherapy, and pelvic radiation. Radiation cystitis is a late complication and it can occur as late as after 10 years of radiation therapy [3], as it was seen in our patient 10 years post radiotherapy. The treatment of radiation cystitis includes CBI for the evacuation of blood, use of hyperbaric oxygen to promote healing of urothelium [4], and surgical options such as cystoscopy, fulguration, and nephrostomy tube insertion.

The CBI with $0.9 \%$ NS is the standard of care for clot evacuation. Elliot et al. studied exfoliation rates of urothelial cells in patients $(\mathrm{N}=5)$ with chronic urinary tract infections and in patients with long-term indwelling catheters. They observed bladder irrigation was associated with an increased disruption of urothelial cells which in turn predisposes the bladder to recurrent infections [5]. In 2014 Paolo et al. reported acute severe pulmonary edema in an 85-year-old male who underwent CBI. Autopsy performed on bladder sample revealed a highly damaged urothelium with mucosal and interstitial edema on histological and immunohistochemical study [6]. Likewise, in our patient bladder irrigation led to systemic absorption of fluid from bladder urothelium that manifested as NAGMA. In our patient, as the serum chloride level started to increase, it decreased serum HCO3 causing H-NAGMA. Once we held bladder irrigation, the chloride levels decreased followed by improvement of $\mathrm{HCO} 3$ and resolution of acidosis. As the patient was on diuretic therapy for pulmonary edema urine studies were considered unreliable. NS has $154 \mathrm{mEq}$ of chloride, and fluid resuscitation with NS leads to an overload of chloride ions into the blood, subsequently leading to $\mathrm{H}-$ NAGMA. Chloride and bicarbonate ions work together to maintain an ionic balance of the cellular space. Hyperchlorhydria favors intracellular transfer of bicarbonate ion to maintain ionic equilibrium, thus reducing its availability to the $\mathrm{pH}$ buffer system ultimately causing net acidosis [7]. As, the patient was not on IV fluids suggesting that systemic absorption (approximately 10L) occurred from bladder urothelium leading to pulmonary edema and acidosis. 
Our case demonstrates that CBI can cause massive absorption of fluids from bladder epithelium causing NAGMA and pulmonary edema. In such cases, ringer lactate with low concentration (109 $\mathrm{mEq}$ ) of chloride as compared to NS (154 mEq) can prove to be a good alternative.

\section{Conclusions}

Continuous bladder irrigation is associated with an increased disruption of urothelial cells which in turn predisposes the bladder to recurrent infections. CBI with $0.9 \%$ NS is the standard of care for clot evacuation. Continuous bladder irrigation may lead to systemic absorption of fluid from bladder urothelium that can manifest as NAGMA. In such cases, ringer lactate with low concentration (109 mEq) of chloride as compared to NS (154 mEq) can prove to be a good alternative.

\section{Additional Information \\ Disclosures}

Human subjects: Consent was obtained by all participants in this study. Conflicts of interest: In compliance with the ICMJE uniform disclosure form, all authors declare the following: Payment/services info: All authors have declared that no financial support was received from any organization for the submitted work. Financial relationships: All authors have declared that they have no financial relationships at present or within the previous three years with any organizations that might have an interest in the submitted work. Other relationships: All authors have declared that there are no other relationships or activities that could appear to have influenced the submitted work.

\section{References}

1. GuhaSarkar S, Banerjee R: Intravesical drug delivery: challenges, current status, opportunities and novel strategies. J Contr Rel. 2010, 148:147-159. 10.1016/j.jconrel.2010.08.031

2. Lewis SA : Everything you wanted to know about the bladder epithelium but were afraid to ask . Am J Physiol Renal Physiol. 2000, 278:867-874. 10.1152/ajprenal.2000.278.6.F867

3. Cox JD, Stetz J, Pajak TF: Toxicity criteria of the Radiation Therapy Oncology Group (RTOG) and the European Organization for Research and Treatment of Cancer (EORTC). Int J Radiat Oncol Biol Phys. 1995, 31:1341-1346. 10.1016/0360-3016(95)00060-C

4. Pasquier D, Hoelscher T, Schmutz J, et al.: Hyperbaric oxygen therapy in the treatment of radio-induced lesions in normal tissues: a literature review . Radiother Oncol. 2004, 72:1-13. 10.1016/j.radonc.2004.04.005

5. Elliott TS, Reid L, Rao GG, Rigby R: Bladder irrigation or irritation?. Br J Urol. 1989, 64:391-394. 10.1111/j.1464-410X.1989.tb06049

6. Paolo MD, Bugelli V, Luca AD, Turillazzi E: Bladder irrigation and urothelium disruption: a reminder apropos of a case of fatal fluid absorption. BMC Urol. 2014, 14:91. 10.1186/1471-2490-14-91

7. Sharma S, Hashmi MF, Aggarwal S: Hyperchloremic Acidosis. Statpearls Publishing, Treasure Island, FL; 2020. 